This item was submitted to Loughborough's Research Repository by the author.

Items in Figshare are protected by copyright, with all rights reserved, unless otherwise indicated.

\title{
Unique rheological response of ultrahigh molecular weight polyethylenes in the presence of reduced graphene oxide
}

PLEASE CITE THE PUBLISHED VERSION

http://dx.doi.org/10.1021/ma501729y

\section{PUBLISHER}

(C) American Chemical Society

\section{VERSION}

SMUR (Submitted Manuscript Under Review)

\section{PUBLISHER STATEMENT}

This work is made available according to the conditions of the Creative Commons Attribution-NonCommercialNoDerivatives 4.0 International (CC BY-NC-ND 4.0) licence. Full details of this licence are available at: https://creativecommons.org/licenses/by-nc-nd/4.0/

\section{LICENCE}

CC BY-NC-ND 4.0

\section{REPOSITORY RECORD}

Liu, Kangsheng, Sara Ronca, Efren Andablo-Reyes, Giuseppe Forte, and Sanjay Rastogi. 2015. “Unique Rheological Response of Ultrahigh Molecular Weight Polyethylenes in the Presence of Reduced Graphene Oxide". figshare. https://hdl.handle.net/2134/17527. 
This document is confidential and is proprietary to the American Chemical Society and its authors. Do not copy or disclose without written permission. If you have received this item in error, notify the sender and delete all copies.

\section{Unique rheological response of Ultra High Molecular Weight Polyethylenes in the presence of reduced graphene oxide}

\begin{tabular}{|r|l|}
\hline Journal: & Macromolecules \\
\hline Manuscript ID: & ma-2014-01729y.R1 \\
\hline Manuscript Type: & Article \\
\hline Date Submitted by the Author: & n/a \\
\hline Complete List of Authors: & $\begin{array}{l}\text { Liu, Kangsheng; Loughborough University, Materials } \\
\text { Ronca, Sara; Loughborough University, Materials } \\
\text { Andablo-Reyes, Efren; Loughborough University, Materials } \\
\text { Forte, Giuseppe; Loughborough University, Materials } \\
\text { Rastogi, Sanjay; Loughborough University, Materials }\end{array}$ \\
\hline
\end{tabular}

\section{SCHOLARONE" Manuscripts}




\title{
Unique rheological response of Ultra High Molecular Weight Polyethylenes in the presence of reduced graphene oxide \\ Kangsheng Liu ${ }^{\dagger}$, Sara Ronca ${ }^{*,+}$, Efren Andablo-Reyes ${ }^{\dagger}$, Giuseppe Forte ${ }^{\dagger}$, Sanjay Rastogi ${ }^{*}, \dot{+}+$ \\ †Department of Materials, Loughborough University, Leicestershire, LE11 3TU, England, U.K. \\ $\ddagger$ Research Institute, Teijin Aramid B.V., Velperweg 76, Arnhem, The Netherlands
}

\begin{abstract}
The paper addresses the difference in electrical conductivities and rheological properties between two nanocomposites of reduced graphene oxide nanosheets (rGON) with commercial Ultrahigh Molecular Weight Polyethylene (C_PE) and a low-entanglement-density UHMWPE synthesized under controlled conditions (Dis_PE), respectively. It has been found that composites made with Dis_PE can reach conductivities at least 100 times higher than those made with C_PE on doing thermal treatment at lower temperatures. However, the difference in the electrical conductivity diminishes when both sets of samples are given a high temperature treatment. This phenomenon is attributed to the difference in morphology of the polymer matrices, for example grain boundaries between the nascent particles. Furthermore, rheological analyses of the two sets of UHMWPE/rGON nanocomposites conclusively demonstrate differences in the interaction between polyethylene chain segments of the disentangled UHMWPE and rGON, compared to the entangled commercial UHMWPE. Both composites show minima in the storage modulus at a specific graphene composition. The strong interaction of polyethylene chains with the filler
\end{abstract}


inhibits disentangled UHMWPE to achieve the thermodynamic equilibrium melt state, whereas in the commercial sample, having a broader molar mass distribution, the higher adhesion probability of the long chains to the graphene surface lowers the elastic modulus of the polymer melt. Correlation between the percolation threshold for electrical conductivity and rheological response of the composites has been also discussed.

\section{INTRODUCTION}

Graphene and its derivatives have attracted considerable attention due to their remarkable electronic, ${ }^{1,2}$ thermal $^{3}$ and mechanical properties ${ }^{4,5}$ and their promising use in high performance nanocomposites. It has been reported that a very low loading of graphene could improve the physical properties of thermoplastic composites due to its high mechanical strength, electrical conductivity and extremely high aspect ratio ${ }^{6}$, with theoretical specific surface of $2630 \mathrm{~m}^{2} / \mathrm{g} .{ }^{7}$ This unique material enables the transformation of an insulator to conductor in the presence of significantly low concentrations compared to the normally used carbon black or carbon nanotubes and also invokes interest in the investigation of chain-filler interaction, which contributes to the dramatic modification of polymer matrix properties ${ }^{8}$.

In the case of UHMWPE, it is known that the polymer mechanical properties improve when the molecular weight increases, but at the expense of the processability. In fact, very high molecular weights correspond to high melt viscosities due to the increasing number of entanglements along chains. ${ }^{9}$ Because of the high entanglement density, the most common method reported for the composites preparation is hot press of a dried UHMWPE-filler mixture ${ }^{10}$, where a segregated structure of filler residing along the grain boundaries of the polymer particles is observed. ${ }^{11,12}$ Outstanding electrical conductivities have been reported using this method. ${ }^{13}$ However a difficulty in sintering of the grain boundaries reduces the contact area between filler 
and chains, thus negatively influencing their interaction and consequently also reducing the mechanical properties of the composites, for example, elongation at break and ultimate strength. ${ }^{14,15}$ Recently, it has been reported that when UHMWPE is synthesized in suitable controlled conditions, reduced number of entanglements can be achieved. ${ }^{16}$ The resultant low entangled UHMWPE (Dis_PE) provides ease in solid-state processing and higher tensile strength and tensile modulus of the uniaxially drawn tapes and the biaxially drawn films. ${ }^{16,17}$ The morphology of the nascent powders of Dis_PE is significantly different from the commercially available UHMWPE. For instance, Dis_PE powders have a more "porous" structure, as shown in Figure 1. The porosity in the powder facilitates the penetration of nano-sized filler into pores and eases the filler dispersion during compression moulding in the melt. The high porosity of the nascent Dis_PE sample also facilitates compression of the powder below its melting temperature. The ease in compression facilitates in maintaining the desired low entanglement density for solid state processing. ${ }^{16}$ Considering these advances in morphology control of UHMWPE, the nanofillers in the disentangled matrix could be homogeneously distributed and sintering of the nascent particles can be achieved. Another method to overcome the problem of sintering can be the polymerization of UHMWPE using GO as a support. This procedure was adopted by Mülhaupt group, where the authors conclusively showed the feasibility in mixing of up to 15 wt $\%$ of UHMWPE in low molecular weight polyethylene. ${ }^{10,18}$ A study on the rheological response of these samples in the linear viscoelastic region will be of interest.

In this publication, we compare the resulting electrical conductivities and rheological response of samples obtained from both C_PE/rGON and Dis_PE/rGON composites after compression moulding. A significant difference in electrical conductivities, measured at room temperature, is observed in the two sets of composites made from the two types of PEs. The observed difference 
in the electrical conductivity after giving the same thermal treatment is associated to the morphological differences and melting behavior of the two polymers. For more details on the melting behavior of the two polymers, the readers are referred to reference 19 . The dissimilarity in the electrical conductivity diminishes when the materials are subjected to high temperature treatment at $230{ }^{\circ} \mathrm{C}$, where the local chain dynamics in the commercial UHMWPE is enhanced. Considering that the configuration of GON and polyethylene chain segments is similar, a strong interaction between the long polyethylene molecules and GON is anticipated. Such an interaction possibility is investigated and its implications on the rheological response of the polymer have been followed by plate-plate rheometry, in the linear viscoelastic region.
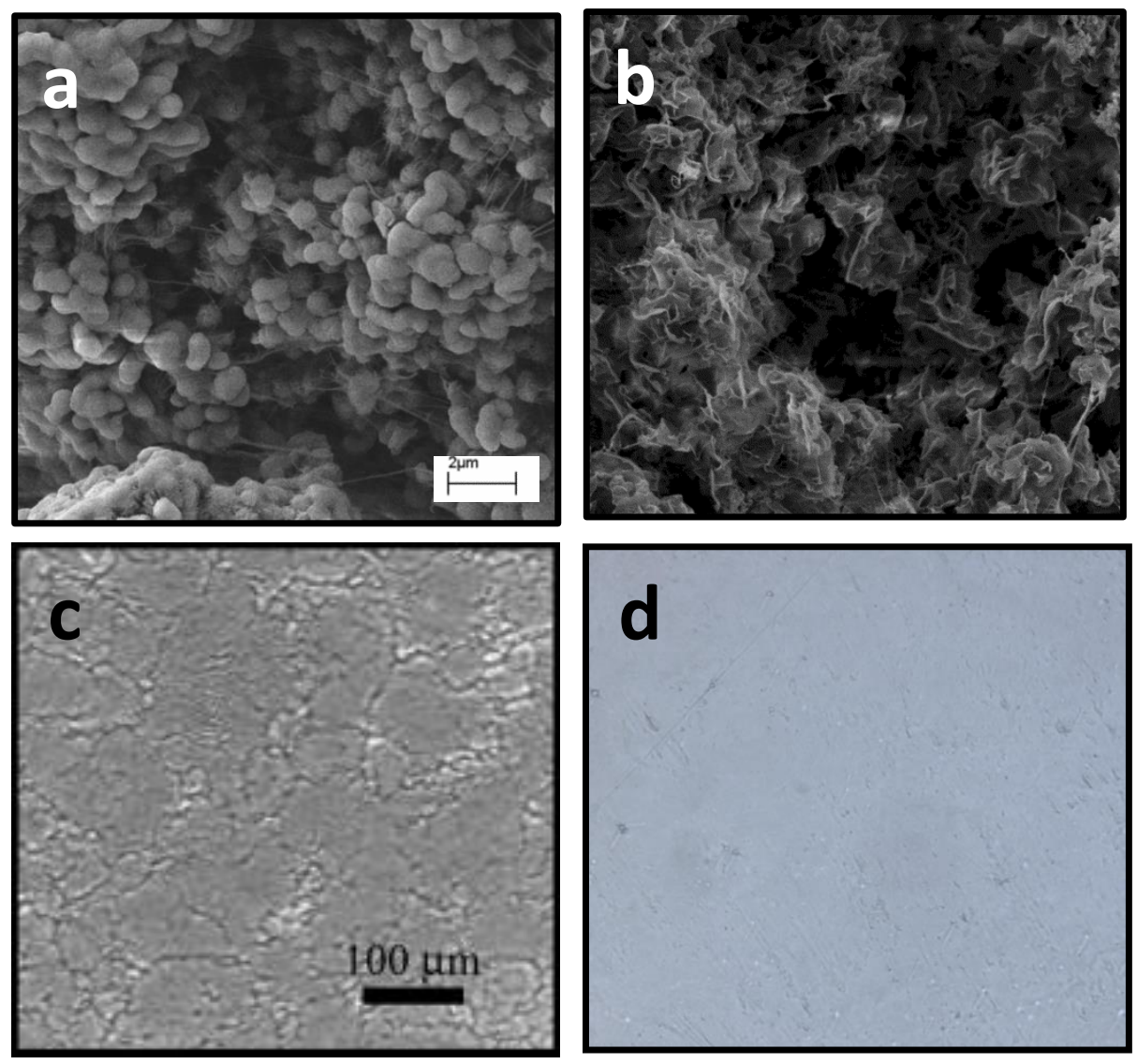

Figure 1. The figure depicts electron ( $\mathrm{a}, \mathrm{b}$ - same scale, 2 microns) and optical micrographs (c, $\mathrm{d}$ - same scale, 100 microns) of the commercial (a, c) and disentangled (b, d) UHMWPEs. The commercial UHMWPE powder is synthesized using a Ziegler-Natta catalyst. The commercial 
sample shows presence of grain boundaries after compression moulding (c), whereas the disentangled UHMWPE powder synthesized using a single-site catalytic system does not show any grain boundaries. The absence of grain boundaries in the disentangled sample is attributed to low bulk density and low entangled state of the sample, the latter enhancing the local chain dynamics. The difference in the bulk density in the two samples is evident from the dense and the porous structure of the commercial (a) and disentangled UHMWPEs (b) observed by electron micrograph.

\section{EXPERIMENTAL}

\subsection{Materials}

GON was synthesized using a modified Hummers method. ${ }^{20}$ Materials for the GON synthesis were purchased from Sigma-Aldrich and used as received. Commercial UHMWPE (C_PE) powder having molecular characteristics reported in Table 1 was also purchased from SigmaAldrich. Disentangled UHMWPE (Dis_PE) with a significantly reduced number of entanglements was synthesized in our lab following the method described elsewhere. ${ }^{16,17}$ Table 1 summarizes some molecular and physical characteristics that are of interest for the present work.

For simplicity, we will indicate each sample with the notation 'X_PE_YY' or 'X_PE/rGON', where $\mathrm{X}=\mathrm{C}$ for commercial, or Dis for disentangled, PE is UHMWPE and YY represents the vol $\%$ amount of rGON present in the sample.

Entanglement density estimation in the disentangled nascent sample has been done by measuring the initial value of the storage modulus obtained on melting of the sample. Table 1 shows the initial storage modulus of the disentangled (0.56 MPa) and the commercial entangled (1.58 MPa) samples recorded at $10 \mathrm{rad} / \mathrm{s}, 160{ }^{\circ} \mathrm{C}$ in the linear viscoelastic region. Under isothermal melt condition, at 10rad/s, the storage modulus of the disentangled sample (Dis_PE) increases from 0.56 MPa to 2.0 MPa (approximately), where the time required for modulus 
build-up shows molar mass dependence as reported elsewhere. ${ }^{19}$ On the contrary, the C_PE sample does not show any substantial increase in the modulus build-up.

Table 1. Overview of physical properties of the two samples of PE investigated in this study.

\begin{tabular}{|c|c|c|c|c|c|}
\hline Polymer & $\begin{array}{l}\text { Particle } \\
\text { diameter } \\
(\mu \mathrm{m})\end{array}$ & $\begin{array}{l}\text { Particle } \\
\text { Morphology } \\
\text { (nascent } \\
\text { powder) }\end{array}$ & $\begin{array}{l}M_{w} \\
\left(10^{6} \mathrm{~g} / \mathrm{mol}\right)\end{array}$ & MWD & $\begin{array}{l}\text { Entanglement density } \\
\text { (starting storage } \\
\text { modulus at } 10 \mathrm{rad} / \mathrm{s} \text { ) }\end{array}$ \\
\hline C_PE & $\sim 50$ & $\begin{array}{l}\text { Highly dense } \\
\qquad\left(0.3 \mathrm{~g} / \mathrm{cm}^{3}\right)^{21}\end{array}$ & 4.4 & 31.1 & $\begin{array}{c}\text { High } \\
(1.58 \mathrm{MPa})\end{array}$ \\
\hline Dis_PE & $\sim 500$ & $\begin{array}{l}\text { Highly porous } \\
\left(0.1 \mathrm{~g} / \mathrm{cm}^{3}\right)^{21}\end{array}$ & 4.8 & 3.1 & $\begin{array}{c}\text { Low } \\
(0.56 \mathrm{MPa})\end{array}$ \\
\hline
\end{tabular}

\subsection{Determination of Molecular Weight and Molecular Weight Distribution of the Polymers}

Weight-average molecular weight $M_{\mathrm{w}}$ and molecular weight distribution (MWD) of both polymers were estimated by rheology using Advanced Rheometrics Expansion System (ARES) as described in the literature $22,23,24$ and the results are shown in Figure 2.
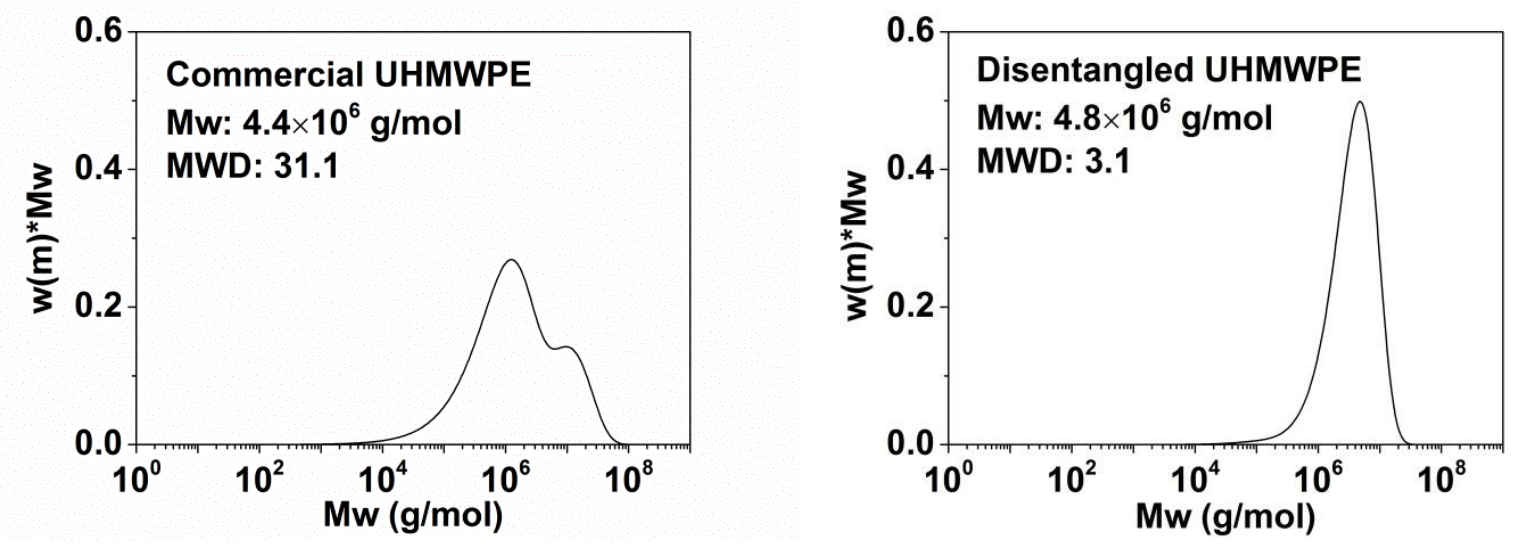

Figure 2. Characterization of molar mass and molar mass distribution as obtained from rheology: (left) C_PE and (right) Dis_PE. 


\subsection{Preparation of GON, rGON and PE/rGON Composites}

The synthesis of GON was done following a modified Hummers Method ${ }^{20}$ with additional modifications as follows. After the oxidation reaction, the resultant material was repeatedly vacuum-filtered and washed, 3 times with $5 \mathrm{wt} \% \mathrm{HCl}$ and subsequently few times with distilled water. The solution thus obtained showed precipitated bottom layer having GON. On continuous washing process by distilled water, with the progressive extraction of GON from the bottom to the top layer, the upper suspension became darker. The average number of water washing steps applied was approximately ten, until the $\mathrm{pH}$ of the suspension changed from $\sim 2$ to $\sim 7$. The dark top layer was extracted and dried on a petri dish at $50{ }^{\circ} \mathrm{C}$ for 2 days. Films of GON, obtained on peeling from the petri dish, were compressed in a hydraulic press.

The GON films having dimensions of approximately $5 \mathrm{~cm}$ x $1 \mathrm{~cm}$ x $20 \mathrm{~cm}$ were compressed with loads of 83 bars for $1 \mathrm{~min}, 415$ bars for $5 \mathrm{~min}, 1245$ bars for $15 \mathrm{~min}$ and 1660 bars for 5 min at temperatures of $160{ }^{\circ} \mathrm{C}, 180{ }^{\circ} \mathrm{C}, 200^{\circ} \mathrm{C}$ and $230{ }^{\circ} \mathrm{C}$, respectively.

A two-step procedure was carried out to prepare the electrically conductive composites with the two types of UHMWPEs: first, the required amount of dried GON was weighed and redispersed in $40 \mathrm{ml}$ of water by 15 min ultrasonication, in parallel the required amount of PE was dispersed in acetone and stirred for $10 \mathrm{~min}$. In the second step, the ultrasonicated homogeneous GON suspension was added to the acetone-suspended PE while stirring. The mixture was stirred in a fume hood until most of the solvent evaporated and the resulting solid was further dried at $40{ }^{\circ} \mathrm{C}$ for 12 hours to remove any residual solvent. The residue, a UHMWPE/rGON composite, was obtained in the form of powder (Figure 5). For increasing the concentration of GON in the PE matrix the amount of GON added to the same amount of PE was increased. The conversion of added GON from wt $\%$ to vol $\%$ was done by considering the density of dried GON to be 2.2 
$\mathrm{g} / \mathrm{cm}^{3},{ }^{25}$ and $0.96 \mathrm{~g} / \mathrm{cm}^{3}$ of PE after compression moulding. Considering the high crystallinity of the nascent UHMWPE samples (> 82\%) the density of the compressed linear UHMWPE sample is obtained close to $0.96 \mathrm{~g} / \mathrm{cm}^{3}$.

Table 2. wt \% to vol \% conversion of the GON in UHMWPE/GON composites.

\begin{tabular}{|l|l|l|l|l|l|l|}
\hline wt \% & 0.1 & 0.3 & 0.5 & 0.8 & 2.0 & 4.0 \\
\hline vol. \% & 0.04 & 0.13 & 0.22 & 0.35 & 0.88 & 1.79 \\
\hline
\end{tabular}

To achieve the reduction of the dispersed GON for electrical conductivity, the dried composite powders were compressed in a hydraulic press at $160^{\circ} \mathrm{C}\left(\right.$ or $\left.230{ }^{\circ} \mathrm{C}\right)$, following the protocol mentioned for obtaining the reduced GON films. Following the compression procedure, composites films of PE/rGON were prepared. In all samples, 0.7 wt \% antioxidant (Irganox 1010, Ciba) to the powder was added to avoid oxidation or degradation of PE during the hot press procedure. WAXD recorded in the transmission mode, on the compressed samples, did not show any orientation.

For rheological studies $~ 0.7 \mathrm{~g}$ of Dis_PE/GON powder was sintered into discs of $50 \mathrm{~mm}$ diameter and $0.6 \mathrm{~mm}$ thickness by compression moulding at a constant temperature of $125{ }^{\circ} \mathrm{C}$ and average force of 20 tons. Similarly, C_PE/GON powder was moulded at a constant temperature of $160^{\circ} \mathrm{C}$. From the compressed powder films smaller discs of $12 \mathrm{~mm}$ diameter were punched.

\subsection{Characterization of GON, rGON and Composites}

A JEOL-2000FX Transmission Electron Microscope (TEM) was used to observe the exfoliated single or few-stacked-layers of GON in water with an applied voltage of $200 \mathrm{kV}$. The thermal stability of GON in air was determined using thermal gravimetric analysis (TGA, TA 
Instrument Q5000IR) with a temperature ramp ranging from $20^{\circ} \mathrm{C}$ to $800{ }^{\circ} \mathrm{C}$ at a heating rate of $10^{\circ} \mathrm{C} / \mathrm{min}$. Field Emission Gun-Scanning Electron Microscope (FEG-SEM) was used for morphological analysis of PE powders. For the analysis, the samples were coated with gold by a sputtering technique. The electrical conductivities of the rGON films and the PE/rGON composites were measured with a Keithley instrument composed of a 2182A nanovoltmeter and a 6220 precision current source. The shape and thickness of the samples were corrected by taking into account the geometric factors according to reference 26.

All rheological measurements were performed in an ARES-LS2 rheometer (TA, Instruments) using a $12 \mathrm{~mm}$ diameter parallel plate geometry. In order to avoid polymer degradation during long time measurements, the samples were kept under a nitrogen atmosphere inside a convection oven. The $12 \mathrm{~mm}$ polymer disc was placed in the rheometer at $110^{\circ} \mathrm{C}$ and the temperature was increased to $160{ }^{\circ} \mathrm{C}$ (approximately $18^{\circ} \mathrm{C}$ above the equilibrium melting temperature of polyethylene, $141.5^{\circ} \mathrm{C}^{27}$ ) with a heating rate of $10^{\circ} \mathrm{C} / \mathrm{min}$. Along this process, an average normal load of $4.0 \mathrm{~N}$ was applied to maintain appropriate contact between the sample and plates. Once the temperature $\left(160^{\circ} \mathrm{C}\right)$ was reached, a small amplitude oscillatory test at a constant frequency of $10 \mathrm{rad} / \mathrm{s}$ and strain $0.1 \%$ (within the linear viscoelastic region) was performed to follow the storage modulus (G') build-up. Data acquisition was started 60 seconds after reaching the experimental temperature of $160^{\circ} \mathrm{C}$. On the fully equilibrated melt state, frequency sweep with angular velocity from $0.001 \mathrm{rad} / \mathrm{s}$ to $100 \mathrm{rad} / \mathrm{s}$ was performed with a constant $0.5 \%$ strain in the linear viscoelastic region on both of the C_PE/rGON and Dis_PE/rGON samples. More detailed description of the rheological procedures can be found in one of our earlier publications. $^{19}$ 


\section{RESULTS AND DISCUSSION}

\subsection{Characterization of GON and rGONs}

Figure 3 shows TEM images of single layered GON in water, demonstrating the successful exfoliation of graphene oxide. The solution from the top layer of the suspension, in the very initial stages of washing, was placed on TEM Cu-grid.
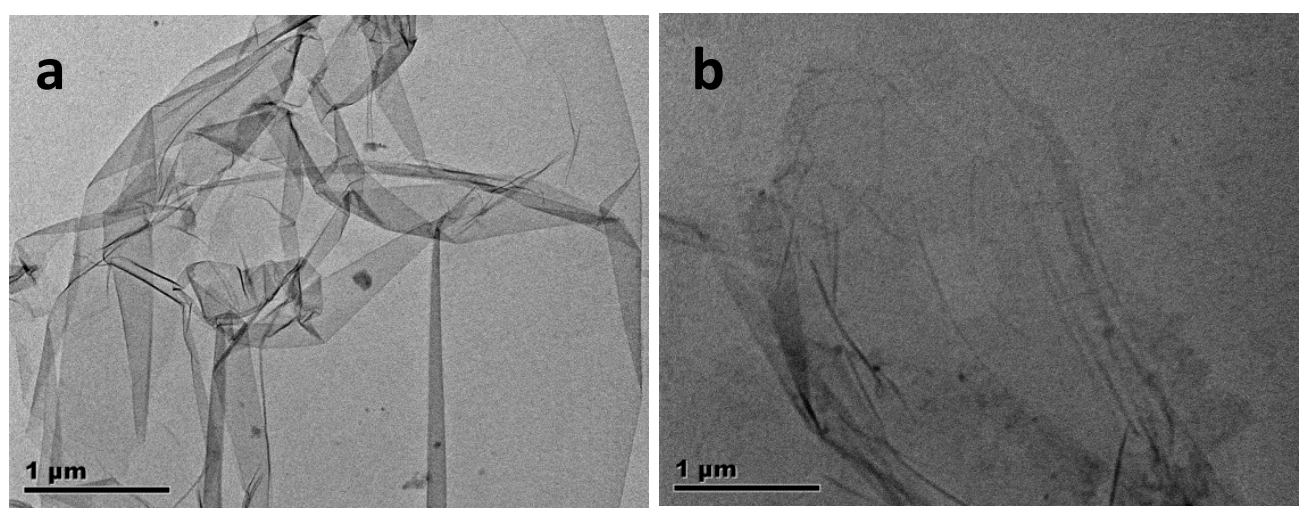

Figure 3. TEM images of exfoliated graphene oxide in water, obtained from the top layer of the suspension.

To achieve electrical conductivity, it is essential that the GON should be reduced to restore the pi-pi bonds. However, reducing the GON prior to its addition to the polymer prevents its homogeneous dispersion in water. For this reason, the GON is added to the polymer in its oxidized form first and the resulting composite is subjected to the desired heat treatment under pressure, with the advantage that in one step the filler is reduced and composite sheets with improved filler dispersion for further testing are prepared. In order to get an indication of the degree of reduction obtained with the heat treatment, the plain GON film was pressed at different temperatures for 26 min under variable pressures. The electrical conductivity of reduced GON $(\mathrm{rGON})$ is measured with the four-point probe technique, and a plot of the conductivity of rGON against the reduction temperature is shown in Figure 4, together with the TGA curve of GON. The average electrical conductivity of rGON on heat treatment at $160{ }^{\circ} \mathrm{C}$ is $76.1 \pm 19.2 \mathrm{~S} / \mathrm{m}$, and 
the conductivity increases with increasing the reduction temperature. rGON reduced at $230{ }^{\circ} \mathrm{C}$ reaches the highest value of $532.0 \pm 5.7 \mathrm{~S} / \mathrm{m}$ and is in trend with the TGA curve, in which the fastest weight loss due to reduction occurs at $231{ }^{\circ} \mathrm{C}$. For comparison, Tour et al. found conductivities of $210 \pm 140 \mathrm{~S} / \mathrm{m}$ for rGON synthesized from Hummers method when the sample was reduced at $300{ }^{\circ} \mathrm{C}$ for $30 \mathrm{~min} .{ }^{28}$ To avoid oxidation or degradation of the polymer matrix, $160{ }^{\circ} \mathrm{C}$ is initially chosen for the preparation of $\mathrm{PE} / \mathrm{rGON}$ composites. The absence of oxidation or degradation became apparent on investigating the rheological and thermal response of the composites that were treated at and above $160{ }^{\circ} \mathrm{C}$ (please see discussion followed by Figures 7,8 , 9 and 10)

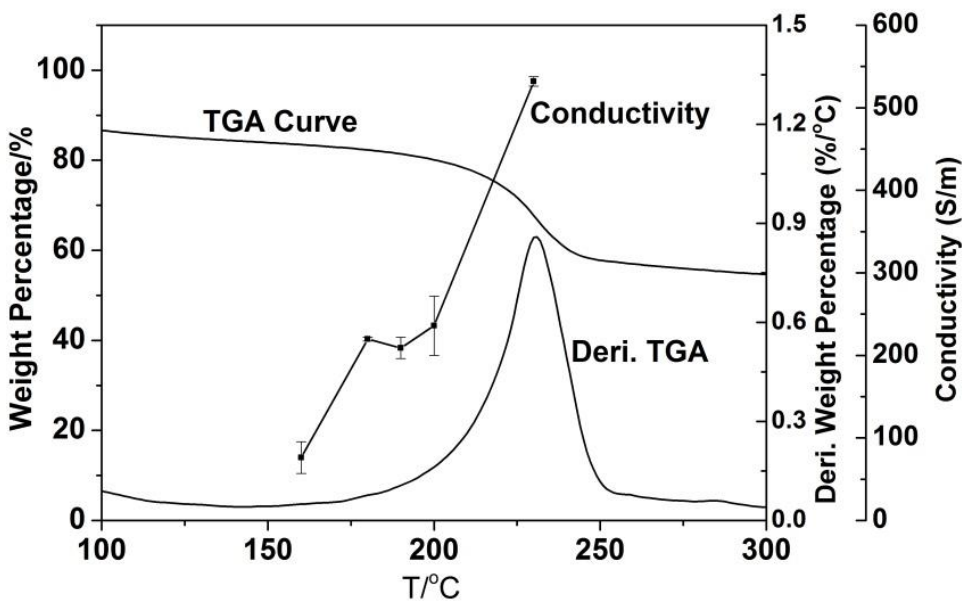

\begin{tabular}{cc}
\hline $\begin{array}{c}\text { Reduction } \\
\text { Temperature } \\
\left({ }^{\circ} \mathbf{C}\right)\end{array}$ & $\begin{array}{c}\text { Conductivity } \\
\text { (S/m) }\end{array}$ \\
\hline $\mathbf{1 6 0}$ & $76 . \pm 19.2$ \\
$\mathbf{1 8 0}$ & $219.8 \pm 2.4$ \\
$\mathbf{1 9 0}$ & $209.2 \pm 13.1$ \\
$\mathbf{2 0 0}$ & $235.9 \pm 35.9$ \\
$\mathbf{2 3 0}$ & $532.0 \pm 5.7$ \\
\hline
\end{tabular}

Figure 4. On the left, plot showing electrical conductivities of reduced graphene oxide against reduction temperatures, together with the TGA curve. On the right, the table summarizes electrical conductivity against the reduction temperature.

\subsection{Electrical Conductivities of C_PE /rGON and Dis_PE/rGON Composites}

Figure 5 depicts $1 \mathrm{~g}$ samples of the plain polymers and their corresponding composites at different filler concentrations. Due to the low bulk density of Dis_PE powder, for the same mass, 
the volume of the Dis_PE composite is much higher.
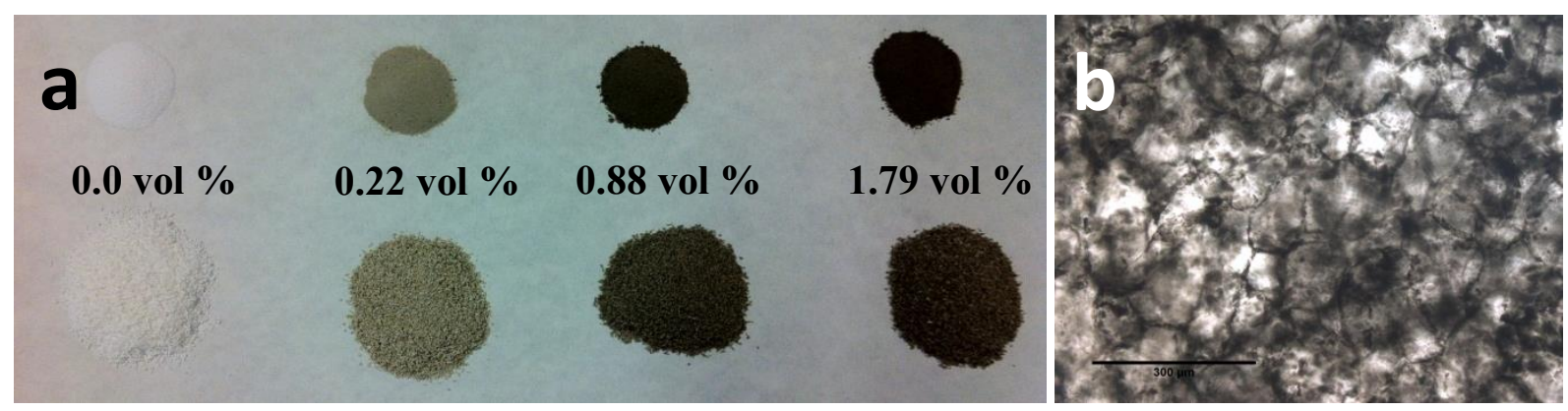

Figure 5. a) Pure PEs and GON-filled PE particles (top series: C_PE; bottom series: Dis_PE). All samples weigh $1 \mathrm{~g}$. Plates for rheological and electrical conductivity measurements were made by compressing these powders at $160{ }^{\circ} \mathrm{C}$ or $230{ }^{\circ} \mathrm{C}$; b) rGON can be observed along the grain boundaries after compression moulding of the C_PE having $0.22 \mathrm{vol} \%$ of the filler. This sample was compressed at $160^{\circ} \mathrm{C}$.

To recall, for simplicity, we will identify each sample with the notation 'X_PE_YY' or 'X_PE/rGON', where $\mathrm{X}=\mathrm{C}$ for commercial, Dis for disentangled, PE is UHMWPE and YY is the vol \% amount of rGON present in the sample. After thermal reduction of the GON during the compression moulding step, the electrical conductivities of C_PE/rGON and Dis_PE/rGON composites were measured using a 4-point probe technique and the resulting values are shown in Figure 6 and listed in Table 3 (the conductivity value of pure PE is taken from reference 29). The conductivity of the samples containing 0.04 vol $\%$ of rGON could not be measured as it was outside the sensitivity of the equipment.

The different conductivity behaviors observed for the two sets of the samples suggest differences in the formation of the filler network. The percolation threshold, defined as the minimal concentration of conductive filler at which a sudden increase in conductivity of the insulating matrix appears, is observed for both matrices to be just below 0.13 vol \% (Figure 6). The conductivities of polymer composites have been investigated based on the modified classical percolation threshold power law: ${ }^{30,31}$ 


$$
\sigma \sim \sigma_{0}[\Phi(f)-\Phi(\mathrm{cri})]^{t}
$$

where $\sigma$ is the conductivity of the composite, $\sigma_{0}$ is the conductivity of the filler, $\Phi(f)$ is the filler concentration; $\Phi(c r i)$ is the critical percolation concentration, and $t$ is the critical exponent, dependent on the dimensions of the lattice and effective aspect ratio of the filler. ${ }^{32}$

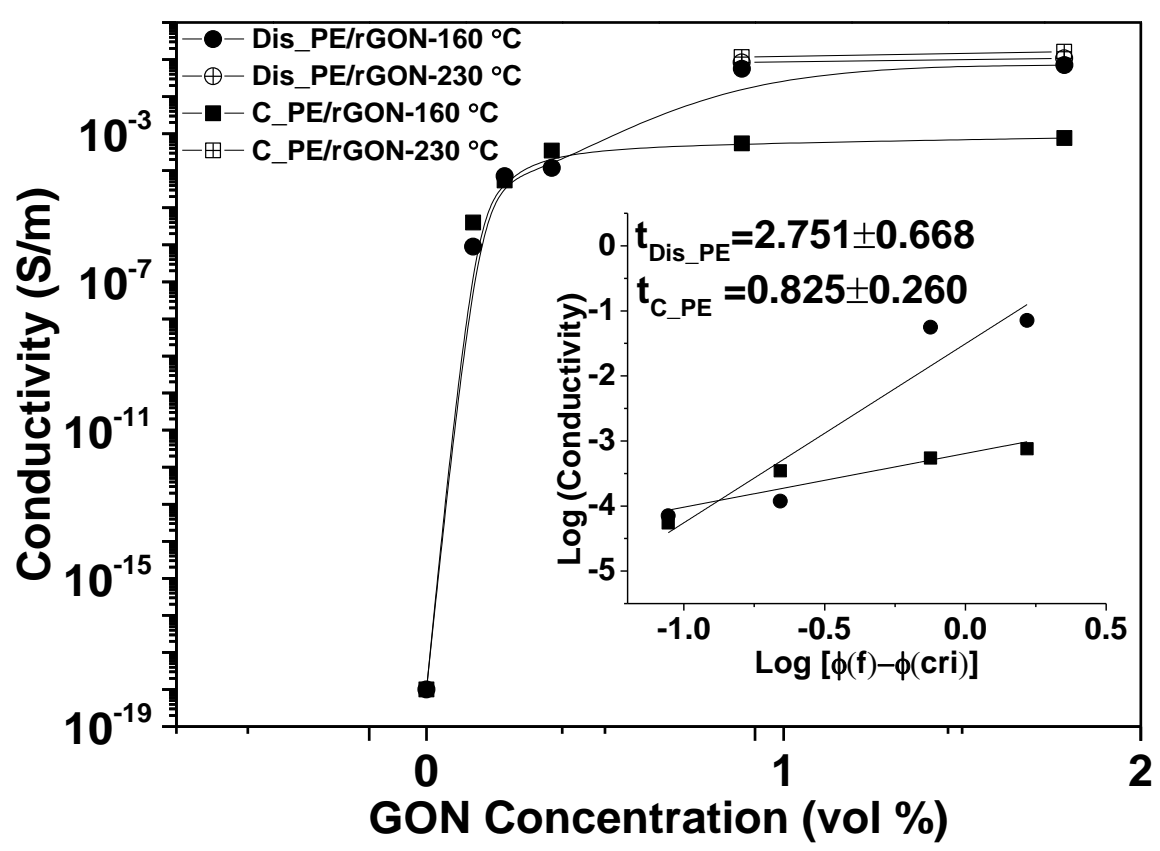

Figure 6. Electrical conductivities of C_PE/rGON (square) and Dis_PE/rGON (circle) composites as function of rGON content. The insert shows the log-log plot of electrical conductivity with $[\Phi(f)-\Phi(c r i)], \Phi(f)$ is the volume fraction of rGON and $\Phi(c)$ is the volume percolation concentration. The conductivity values are reported in Table 3.

Table 3. Conductivity values from Figure 6.

\begin{tabular}{|l|l|l|}
\hline Sample & $\begin{array}{l}\text { Compression } \\
\operatorname{Temp}\left({ }^{\circ} \mathbf{C}\right)\end{array}$ & Conductivity (S/m) \\
\hline C_PE_0.13 & 160 & $4.00 \times 10^{-6}$ \\
\hline
\end{tabular}




\begin{tabular}{|l|l|l|}
\hline C_PE_0.22 & 160 & $5.46 \times 10^{-5}$ \\
\hline C_PE_0.35 & 160 & $3.48 \times 10^{-4}$ \\
\hline C_PE_0.88 & $\mathbf{1 6 0}$ & $\mathbf{5 . 4 7 \times 1 0 ^ { - 4 }}$ \\
\hline C_PE_1.79 & $\mathbf{1 6 0}$ & $\mathbf{7 . 5 5} \times \mathbf{1 0}^{-4}$ \\
\hline & & \\
\hline Dis_PE_0.13 & 160 & $8.93 \times 10^{-7}$ \\
\hline Dis_PE_0.22 & 160 & $7.07 \times 10^{-5}$ \\
\hline Dis_PE_0.35 & 160 & $1.19 \times 10^{-4}$ \\
\hline Dis_PE_0.88 & $\mathbf{1 6 0}$ & $\mathbf{5 . 6 0 \times 1 0 ^ { - 2 }}$ \\
\hline Dis_PE_1.79 & $\mathbf{1 6 0}$ & $\mathbf{7 . 1 0 \times 1 0 ^ { - 2 }}$ \\
\hline Cis_PE_0.88 & 230 & $1.62 \times 10^{-1}$ \\
\hline C_PE_0.88 & 230 & $0.83 \times 10^{-1}$ \\
\hline C_PE_1.79 & 230 & $1.08 \times 10^{-1}$ \\
\hline & & \\
\hline Dis_PE_1.79 & 230 & \\
\hline & & \\
\hline & & \\
\hline & & \\
\hline
\end{tabular}

From Figure 6 it can be concluded that the conductivities measured for the two composites, compressed at $160{ }^{\circ} \mathrm{C}$, just after the percolation threshold are rather different and considerably higher in the case of Dis_PE/rGON composites. It is observed that the conductivities of Dis_PE/rGON become at least 100 times higher than that of C_PE/rGON with filler concentrations $\geq 0.88 \mathrm{vol} \%$. The critical exponent value of C_PE/rGON samples is around 0.83 and more interestingly a much higher critical exponent of about 2.75 is determined for Dis_PE/rGON samples. At low loadings of GON (close to the percolation threshold), the filler is 
homogeneously dispersed in both commercial and disentangled PE composites, thus similar conductivity values in the two composites are observed. ${ }^{33,34}$ For higher loadings of GON in the C_PE, the filler is likely to stack along the grain boundaries of the powder particles, thus resulting in just a slight increase of conductivity when the filler content is increased from 0.35 to 1.79 vol \%. On the contrary in Dis_PE because of the porous structure of the nascent powder, and the lower initial melt viscosity ${ }^{17,35}$ of the polymer; the presence of the filler into the porous polymer powder is facilitated. This results into homogeneous dispersion of GON platelets without their aggregation. Thus, compared to C_PE, for the same concentration of GON the filler in Dis_PE forms a more efficient network. The resultant effect is that for the same concentration of GON the conductivity increases by more than 100 times in Dis_PE compared to C_PE composites on increasing the filler content from 0.35 to 0.88 vol $\%$. The difference in the electrical conductivity vanishes when both samples are heat treated at a higher temperature, $230{ }^{\circ} \mathrm{C}$. The loss in the difference is attributed to the enhanced chain mobility at the high temperature.

From electrical conductivity measurements it is evident that the presence of grain boundaries and the chain dynamics have strong implications on the interaction between ethylene chain segments and graphene. To have further insight on the difference in the chain-filler interactions, rheological studies on the composites have been performed in the two sets of samples, at $160{ }^{\circ} \mathrm{C}$. To recall, at this 'low' temperature the commercial sample maintains the grain boundary arising from the nascent powder morphology, whereas the disentangled sample loses its initial particle morphology. 


\subsection{Rheological Analysis}

\section{$\underline{\text { Rheological analysis of C_PE/rGON and Dis_PE/rGON composites }}$}

The elastic modulus (G') build-up curves for C_PE/rGON and Dis_PE/rGON composites are shown in Figure 7a and Figure 7b, respectively. The corresponding curves obtained for the polymers without any filler are also shown for comparison. The lower value of the initial storage modulus in the Dis-PE, compared to C_PE, suggests that the molar mass between entanglements $\left(M_{\mathrm{e}}\right)$ achieved on melting of the disentangled nascent powder is much larger. In accordance with the earlier findings, the commercial sample hardly shows any modulus build-up with time, whereas the disentangled sample shows modulus build-up with the transformation of melt from its non-equilibrium to equilibrium state i.e. decrease in $M_{\mathrm{e}}$ till it reaches the equilibrium value. We would like to mention that though metastable crystalline states in polymer science have been studied extensively ${ }^{36}$ the non-equilibrium melt states have not been investigated in detail. 

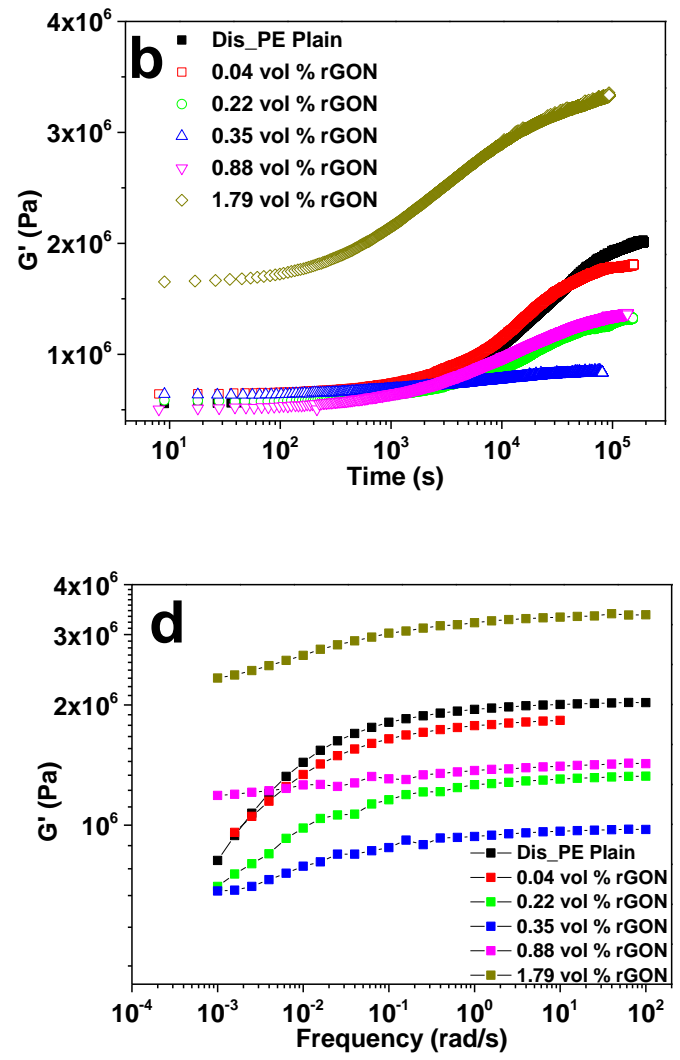

Figure 7. a) G' build-up of Dis_PE/rGON composites; b) G' build-up of C_PE/rGON composites; c) Frequency sweep of C_PE/rGON composites; and d) Frequency sweep of Dis_PE and its composites. The C_PE samples were compressed at $160{ }^{\circ} \mathrm{C}$, whereas the Dis_PE samples were compressed at $125^{\circ} \mathrm{C}$. The low compression temperature for the Dis_PE sample was used to follow the entanglement formation in time sweep experiments (Figure b). Followed by the time sweep experiments (Figures a and b), on the same samples, the frequency sweep experiments were performed (Figures $\mathrm{c}$ and d). All rheological studies were done at $160{ }^{\circ} \mathrm{C}$ in the linear viscoelastic region.

In Figure 7a, the increase in elastic modulus build-up of C_PE/rGON composites is closer to the plain commercial polymer. The slight increase in the final value of G', which increases with the filler concentration, can be attributed to the mechanical enhancement from the high modulus graphene. The increase in the modulus with the addition of filler is in accordance with the earlier findings reported in literature..$^{30,37,38}$ Contrary to the commercial polyethylene, the modulus 
build-up time of Dis_PE/rGON composites shows a strong dependence on the rGON content in the polymer matrix. Though the initial value of G', observed on melting of the crystals, is independent of the rGON content (at least for $\mathrm{rGON}<1.79$ vol \%), the modulus build-up time is strongly influenced by the volume fraction of the filler in the polymer matrix. For example, the polymer having no filler shows the fastest modulus build-up compared to the samples having fillers. Among the samples with fillers, the sample with 0.35 vol $\%$ of the rGON shows the slowest modulus build-up. This suggests a strong molecular interaction between the polyethylene chain segments and the filler that inhibits the transformation of melt from its non-equilibrium to equilibrium state. The gradual increase in the modulus build-up time occurs with the increasing amount of rGON from 0.04 to $0.35 \mathrm{vol} \%$. On increasing the volume fraction from $0.35 \mathrm{vol} \%$ to 0.88 vol $\%$ the modulus build-up time tends to decrease. This decrease in the modulus build-up time suggests that the filler is more homogeneously distributed for 0.35 vol\%. On increasing the filler concentration, beyond $0.35 \mathrm{vol} \%$, the filler tend to aggregate causing increase in the storage modulus, see Figure 7b.

Important to notice is that unlike the commercial sample composites, where the final plateau modulus value on the addition of filler is higher, in the Dis-PE composites the final plateau modulus reaches a minimum followed by an increase, as shown in Figure 8a. The minimum achieved in the final value of the plateau modulus of the composite $(0.35$ vol \% of GON) can be attributed to the maximum interaction of the rGON network with the polyethylene chains in disentangled UHMWPE, which forbids the chains from further entanglement formation resulting in higher molar mass between entanglements $M_{\mathrm{e}}$; hence reduces the plateau values in accordance with the equation: ${ }^{39}$ 


$$
G_{N}^{0}=\frac{g_{N} \rho R T}{<M_{e}>}
$$

where $\mathrm{g}_{\mathrm{N}}$ is a numerical factor ( 1 or $4 / 5$ depending upon convention), $\rho$ is the polymer melt density, $\mathrm{R}$ is the gas constant and $\mathrm{T}$ is the absolute temperature.

The disappearance of the terminal region for the composite having $0.35 \mathrm{vol} \%$ of GON suggests maximum interaction between polyethylene chain segments and rGON, Figure 8. For the same concentration of $\mathrm{rGON}, 0.35 \mathrm{vol} \%$, the increase in electrical conductivity for the Dis_PE/rGON composite is also observed, Figure 6 . This suggests that at the specific concentration of 0.35 vol $\%$ the rGON is well dispersed, and forms an efficient continuous network, which provides percolation threshold for electrical conductivity and high surface to volume ratio for maximum number of chain segments to attach on the surface of rGON. From Figure 7b, 7d and Figure $8 \mathrm{a}$ it is evident that at and above 0.88 vol \% the plateau value of Dis_PE samples increases with increase in the filler content, suggesting aggregation of the GON layers, contributing to the increase in the storage modulus. The aggregation also retards increase in the electrical conductivity with the increasing filler concentration (Figure 6).
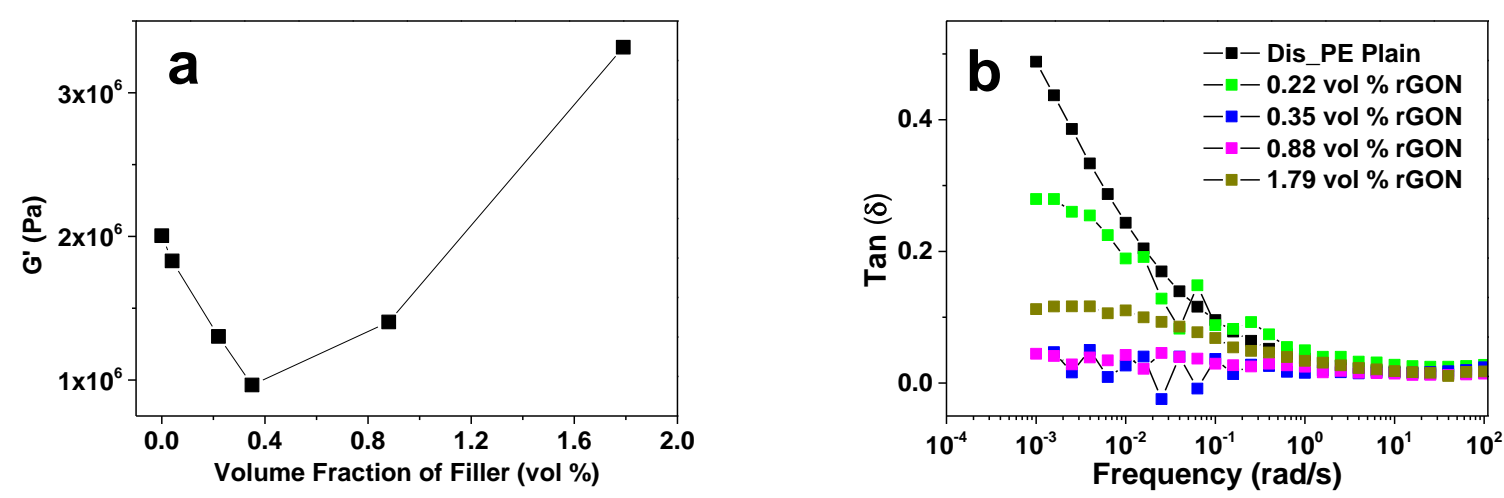

Figure 8. a) Storage modulus of Dis_PE/rGON composites at plateau (10 rad/s) of frequency sweep, shown in Figure 7d. b) Corresponding changes in phase angle, $\tan \delta$, as a function of frequency for different Dis_PE/rGON composites. The phase angle is obtained from the frequency sweep data shown in Figure 7d. All experiments were performed under isothermal condition, $160{ }^{\circ} \mathrm{C}$ in the linear viscoelastic region. 
The commercial samples show increment of storage modulus with increasing filler content at the low frequencies, Figure 7c, suggesting contribution of fillers in the mechanical enhancement mainly. On the contrary, similar to the modulus build-up, the frequency response of Dis_PE composites shows strong influence of rGON concentration (Figure 7d). The elastic to viscous transition of the polymer melt diminishes with the increasing concentration of graphene from $0.04 \mathrm{vol} \%$ to $0.88 \mathrm{vol} \%$. The composite having $0.88 \mathrm{vol} \%$ of rGON shows a plateau stretching over a broad frequency range - indicating inhibition of chain reptation within the experimental time scale. The difference in the rheological behaviors between the two sets of samples, C_PE and Dis_PE, is attributed to the entanglement density of the polymer having different powder morphology, which holds the key to the dispersion of the filler as well as the level of interaction between the filler and the polymer chains. This means that by suppressing the influence of grain boundaries between the nascent particles, by enhancing the chain dynamics, the commercial samples shall also show trend similar to the disentangled UHMWPE samples.

With the increasing concentration of GON, in the measured frequency region, the response of the phase angle (Figure 8b) combined with the storage modulus (G') (Figures 7a, 7c and 7d) rules out any possibility of thermo-oxidative degradation. The chain-scission or cross-linking would have excluded the observed decrease in the terminal region, or plateau in the elastic region, in the sample having higher concentration $(1.79 \mathrm{vol} \%)$ of GON. Thus the rheological response of the C_PE and the Dis_PE, Figures 7c, 7d and 8b, in the frequency sweep experiments conclusively demonstrate the absence of thermo oxidative degradation in the presence of GON. The absence becomes more evident while analysing the rheological response of the commercial sample compressed at even higher temperature $230{ }^{\circ} \mathrm{C}$. See the rheological response of the sample reported in Figure 9. The possibility of thermal oxidation is further ruled out by 
following the crystallization kinetics, where the enthalpy of melting and crystallization does not change with the annealing time (ranging from 5 min to $12 \mathrm{hrs}$ ) in melt $\left(160{ }^{\circ} \mathrm{C}\right)$ in the presence of GON.

Rheological analysis of $\mathrm{C} \_\mathrm{PE} / r G O N$ composites compressed at $230^{\circ} \mathrm{C}$

In order to suppress the grain boundaries effect in the commercial UHMWPE the samples are heated to higher temperatures, $230{ }^{\circ} \mathrm{C}$. The increase in temperature enhances the chain dynamics thus providing greater interaction between polymer chains and the filler. Rheological experiments in the conditions same as Dis_PE composites are performed at $160{ }^{\circ} \mathrm{C}$. Similar to disentangled UHMWPE, Figure 9a and Figure 9c, composites from the commercial sample also show decrease in the plateau modulus with the increasing filler content, where the minimum in the storage modulus is observed at 0.88 vol \% of graphene loading. Frequency response of the composites is summarized in Figure 9b. The drop in the storage modulus and parallel shift in the frequency response with the increasing concentration of rGON suggests decrease in the melt viscosity. These findings, combined with those from the disentangled UHMWPE composites, conclusively suggest that, upon suppression of the grain boundaries influence at high temperature, it is feasible to disperse fillers more homogeneously in the matrix of the commercial sample, thus providing better interaction between polymer chains and graphene that hinders the chain mobility. Similar trends have been also reported in earlier works of commercial UHMWPE/SWCNTs nanocomposites, showing that selective physicoabsorption of the high molar mass fraction onto the filler surface promotes appreciable decrease in the storage modulus and dynamic complex viscosity at low frequencies of the composites. ${ }^{40}$ The drop in viscosity is in agreement with the other recent findings reported elsewhere with different composites systems, for example polystyrene filler with cross-linked polystyrenes ${ }^{41}$ and UHMWPE/silica 
nanocomposites $^{42}$. Jain et. al. also reported drop in viscosity of polypropylene's at a specific concentration of silica particles. ${ }^{43}$ Recently, influence of molecular weight and chain branching on melt viscosity of PE/CNTs has been addressed by Vega et al. ${ }^{44}$ In this publication the authors have investigated rheological response of low density polyethylene, having molar mass ranging between $100 \mathrm{~K}$ to $300 \mathrm{~K} \mathrm{~g} / \mathrm{mol}$, in the presence of CNTs. The authors have conclusively shown that, with the increasing molar mass, influence of CNTs on nucleation of polyethylenes decreases, which suggests higher interaction of CNTs with the longer polymerchains. The interaction of ethylene segments with carbon black has been conclusively shown by Litvinov and co-workers while investigating EPDM/Carbon black composites by NMR, where the authors reported the adsorption of EPDM to the surface of carbon black. ${ }^{45,46}$

It has to be noted that the maximum decrease of plateau value of commercial UHMWPE samples is observed at 0.88 vol \% while for disentangled samples, the maximum decrease in the modulus is observed at $0.35 \mathrm{vol} \%$. The difference is attributed to the dispersion of the filler and the molar mass distribution. Although the commercial samples were heat-treated at higher temperatures, the initial high entanglement density still restricts the chain mobility. Thus the entangled chains in the commercial samples cannot move as freely as the disentangled PE chains. This restricted chain mobility refrains from homogeneous dispersion of the filler and its interaction with the chains in the entangled polymer melt. 

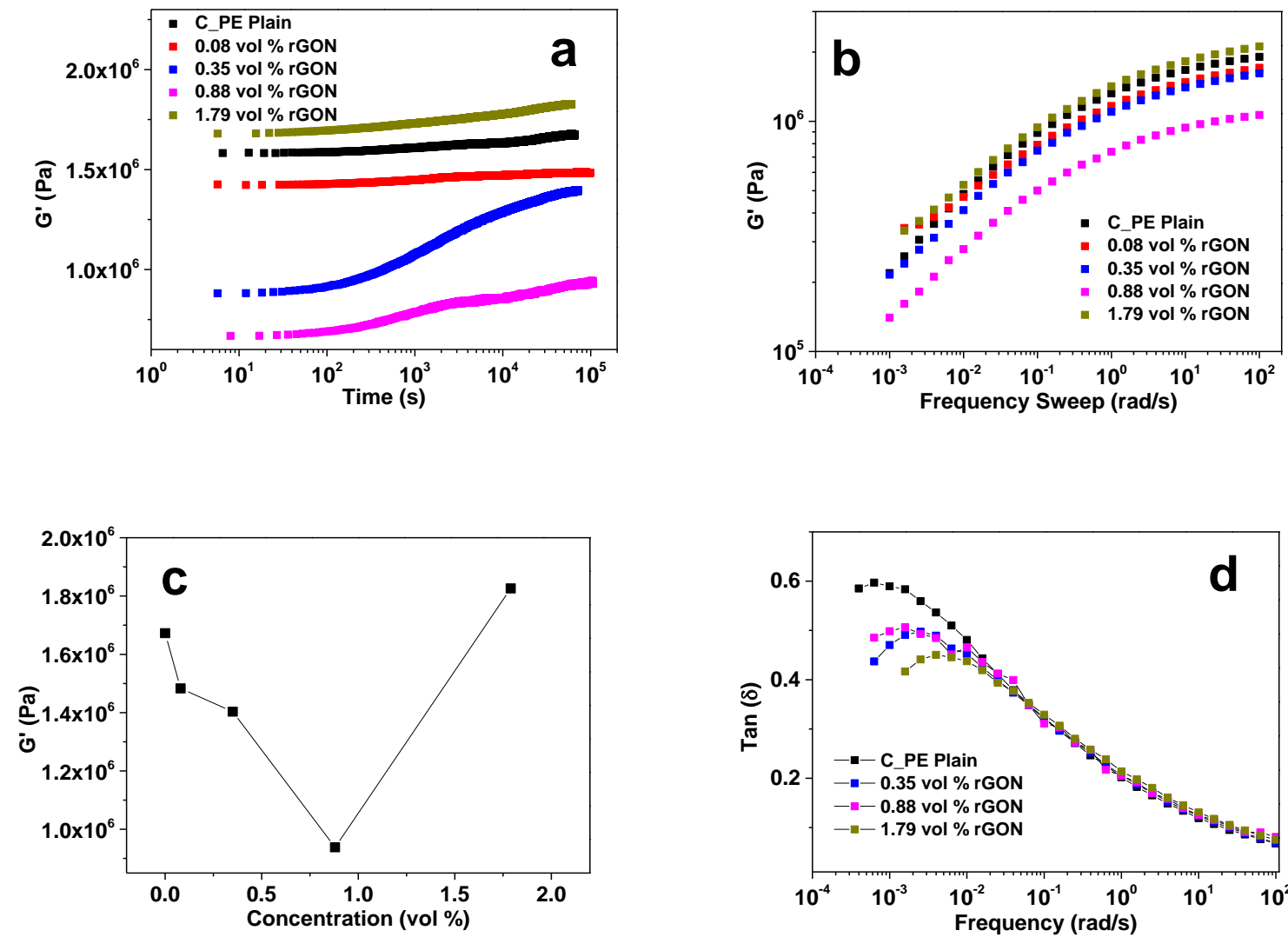

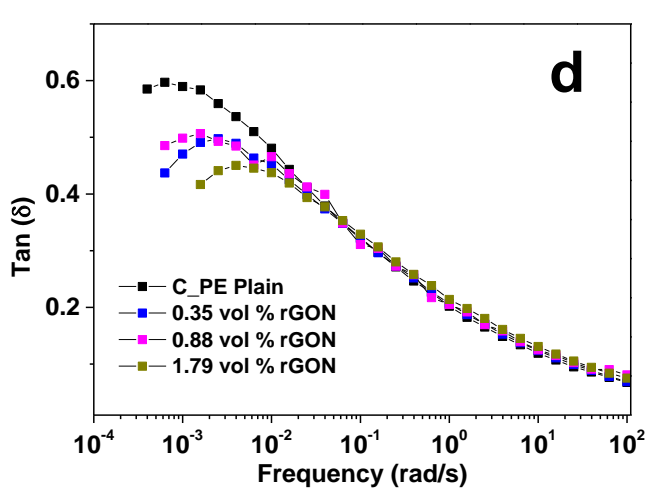

Figure 9 a) Storage modulus, G', build-up of C_PE/rGON composites; b) Frequency sweep of C_PE/rGON composites; c) Storage modulus of C_PE/rGON composites at plateau of frequency sweep (10 rad/s); d) Corresponding changes in phase angle, $\tan \delta$, as a function of frequency for different C_PE/rGON composites. All experiments were performed under isothermal condition at $160{ }^{\circ} \mathrm{C}$ in the linear viscoelastic region though these samples were previously subjected to heat treatment of $230{ }^{\circ} \mathrm{C}$ for suppression of the grain boundaries influence in dispersion of the filler. The difference in phase angle (Figure $9 \mathrm{~d}$ to $8 \mathrm{~b}$ ) can be attributed to the difference in molar mass distribution, as it is apparent from the terminal region of the two polymers (Figures $9 \mathrm{~b}$ and $7 \mathrm{~d}$ ), respectively.

To investigate on the possible thermo-oxidative degradation on UHMWPE, in the presence of GON, DSC experiments have been performed to follow crystallization kinetics and the associated melt enthalpy. Figure 10 compares melt enthalpy of the disentangled UHMWPE without GON and the composite with $0.35 \mathrm{vol} \%$ of GON. From the figure it is apparent that the melt enthalpy in the disentangled UHMWPE decreases with the increasing entanglement density, 
whereas the composite with GON shows no decrease in melt enthalpy with time. These observations are in agreement with the rheological response of the materials depicted in Figure 7. For example, the polymer with 0.35 vol $\%$ of GON does not show any modulus build up (Figure 7b), i.e entanglement formation, thus the entanglement density of this composite remains constant and the polymer stays in the non-equilibrium melt state. No change in the entanglement density, combined with the absence of thermo-oxidative degradation or cross-linking, with time result in the constant melt enthalpy. Whereas the polymer without GON shows modulus build-up and the associated increase in the entanglement density, reduction in molar mass between entanglements, and consequently drop in the melt enthalpy. These findings on influence of entanglements on melting enthalpy are in accordance with the earlier literature. ${ }^{47,48}$
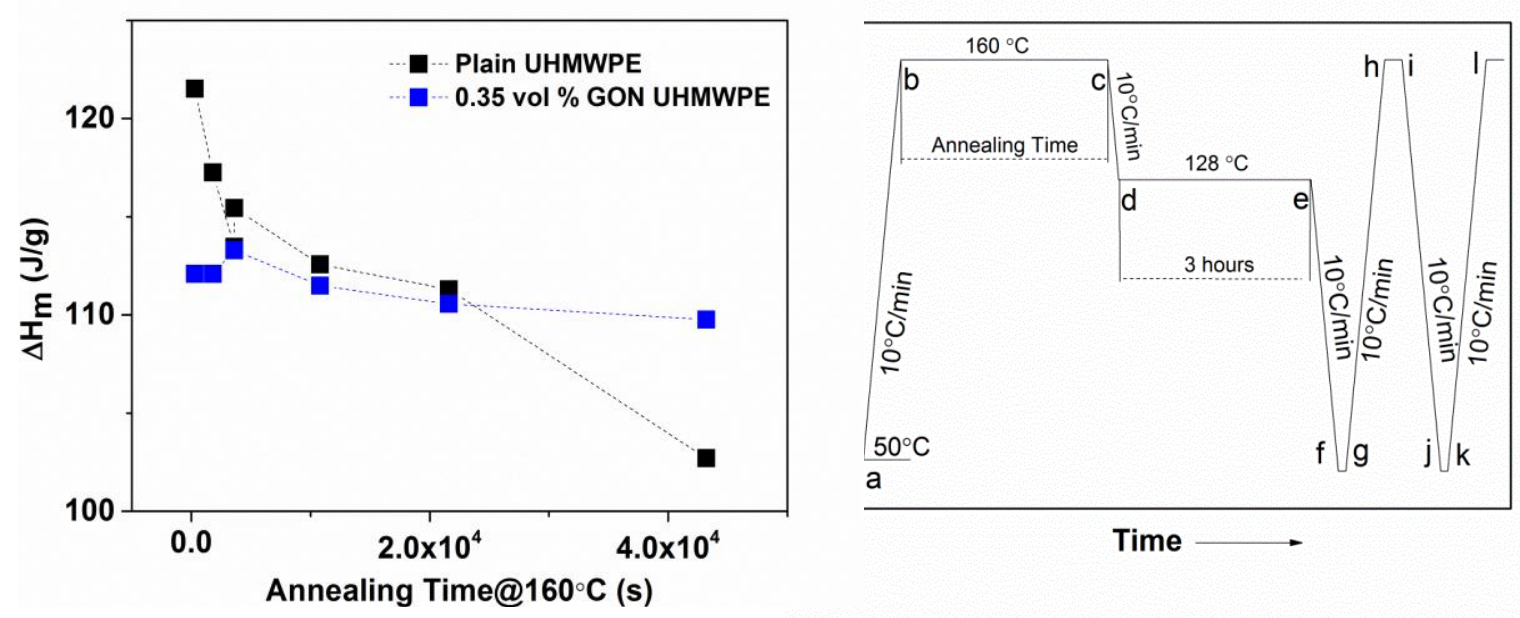

Figure 10. Melt enthalpy of the polymer crystallized after annealing in melt at different time. The samples of mass ranging between 1.4-1.6 mg were placed in Tzero pan of TA-DSC 2000. The figure on right shows the DSC protocol where the enthalpy measurements on the left have been recorded on each new sample during the cycle $g-h$. The annealing time in melt was varied from 5 min to 12 hrs during the protocol b-c.

These rheological findings will be discussed in more details in a follow-up publication, where the influence of rGON on chain configuration and associated crystallization behavior ${ }^{49}$ will be 
further discussed by coupling solid state NMR studies and DSC analysis. The reduced melt viscosity at a specific concentration of the filler opens the new possibility of mixing UHMWPE/rGON composites to low molar mass polyolefins thus opening the prospects of enhancing mechanical properties such as tensile modulus and strain hardening of the easily processable polyolefins. This subject will be also addressed in the following publications.

\section{CONCLUSIONS}

The paper reports the difference in electrical conductivities and rheological response of Dis_PE/rGON and C_PE/rGON composites. A tentative explanation of the observed difference in the electrical conductivity is attributed to (a) the difference in the bulk density of the commercial and the disentangled UHMWPE nascent powders, (b) and the different chain dynamics of the two polymers. The ease in dispersion of the filler in Dis_PE is attributed to the porous matrix and low melt viscosity of the polymer, influencing the electrical conductivity. However, the difference in the electrical conductivity between the commercial and the disentangled UHMWPE vanishes when both sets of samples are subjected to the high temperature treatment, where the grain boundary difference in the nascent powder particles is suppressed. The rheological analyses of the two sets of UHMWPE/rGON nano-composites conclusively demonstrate differences in the interaction between the chains and rGON, mainly caused by the grain boundaries present in the nascent powder morphology of the entangled polymer. After suppressing the grain boundary differences in the nascent powders, the disentangled PE samples show minima in the storage modulus at 0.35 vol \% graphene content and commercial samples show minima at 0.88 vol $\%$ graphene content. The minimum value appears when the chain mobility is arrested by the strong interaction between polymer chains and 
graphene. The strong interaction of the polyethylene chains with the filler inhibits the disentangled UHMWPE to achieve the thermodynamic equilibrium melt state, within the experimental time scale. In the commercial sample, having a larger molar mass distribution, the higher adhesion probability of the long chains to the graphene surface lowers the elastic modulus of the polymer melt. These findings further confirm that the contact surface area of molecular chain segments of polyethylene and rGON becomes similar in the Dis_PE and the commercial samples once the difference in the grain boundaries is decreased-thus resulting in similar electrical conductivity and rheological behaviors of the two sets of nanocomposites. At the GON concentration of $0.35 \mathrm{vol} \%$ in the Dis_PE composite, the electrical conductivity starts increasing significantly and also the plateau reaches minimum in the storage modulus; this demonstrates that at this specific concentration, an effective continuous filler-filler network is formed where the maximum surface to volume ratio, for the adhesion of ethylene segments in the homogeneously dispersed GON in UHMWPE matrix, is achieved.

\section{AUTHOR INFORMATION}

\section{Corresponding Authors:}

*(S.R.) E-mail: S.Rastogi@lboro.ac.uk; *(S.R.) E-mail: S.Ronca@lboro.ac.uk

\section{ACKNOWLEDGEMENT}

The authors wish to acknowledge financial support provided by Loughborough University, UK and Teijin Aramid, The Netherlands. 


\section{References}

(1) Novoselov, K. S.; Geim, A. K.; Morozov, S. V.; Jiang, D.; Zhang, Y.; Dubonos, S. V.; Grigorieva, I. V.; Firsov, A. A. Science 2004, 306, 666-669.

(2) Nilsson, J.; Neto, A. H. C.; Guinea, F.; Peres, N. M. R. Phys. Rev. Lett. 2006, 97, 266801.

(3) Balandin, A. A.; Ghosh, S.; Bao, W. Z.; Calizo, I.; Teweldebrhan, D.; Miao, F.; Lau, C. N. Nano. Lett. 2008, 8 (3), 902-907.

(4) Koziol, K.; Vilatela, J.; Moisala, A.; Motta, M.; Cunniff, P.; Sennett, M.; Windle, A. Science 2007, 318, 1892-1895.

(5) Lee, C. G.; Wei, X. D.; Kysar J. W.; Hone, J. Science 2008, 231, 385-388.

(6) Krompiewski, S. Nanotechnology 2011, 22, 445201.

(7) Stoller, M. D.; Park, S.; Zhu, Y.; An, J.; Ruoff, R. S. Nano. Lett. 2008, 8 (10), 3498-3502.

(8) Mittal, V. Polymer graphene nanocomposites; The royal society of chemistry. 2013.

(9) De Gennes, P. G. Scaling concepts in polymer physics; Cornell University Press: Ithaca and London, 1979.

(10) Sturzel, M.; Kempe, F.; Thomann, Y.; Mark, S.; Enders, M.; Mülhaupt R. Macromolecules 2012, 45, 6878-6887.

(11) Hu, H.; Zhang, G.; Xiao, L.; Wang, H.; Zhang, Q.; Zhao, Z. Carbon 2012, 50 (12), 4596.

(12) Zhang, C.; Ma, C. A.; Wang, P.; Sumita, M. Carbon 2005, 43, 2544-2553. 
(13) Pang, H.; Xu, L.; Yan, D. X.; Li, ZM. Prog. Polym. Sci. 2014, DOI:

10.1016/j.progpolymsci.2014.07.007.

(14) Mierczynska, A.; Mayne-L'Hermite, M.; Boiteux, G.; Jeszka, J. K. J. Appl. Polym. Sci. 2007, 105, 158-168.

(15) Bakshi, S. R.; Tercero, J. E.; Agarwal, A. Composites Part A 2007, 38, 2493-2499.

(16) Rastogi, S.; Yao, Y.; Ronca, S.; Bos, J.; van der Eem, J. Macromolecules 2011, 44 (14), 5558-5568.

(17) Rastogi, S.; Kurelec, L.; Lippits, D. R.; Cuijpers, J.; Wimmer, M.; Lemstra, P. J. Biomacromolecules 2005, 6, 942-947.

(18) Sturzel, M.; Thomann, Y.; Mark, S.; Enders, M.; Mülhaupt, R. Macromolecules, 2014, 47 (15), 4979-4986.

(19) Pandey, A.; Champouret, Y.; Rastogi, S. Macromolecules 2011, 44 (12), 4952-4960.

(20) Liu, P.; Gong, K.; Xiao, P.; Xiao, M. J. Mater. Chem. 2000, 10, 933-935.

(21) Rastogi, S.; Ronca, S. US patent WO 2010/079173A1, 2010.

(22) Mead, D. J. Rheol. 1994, 38, 1797-1827.

(23) Talebi, S.; Duchateau, R.; Rastogi, S.; Kaschta, J.; Peters, G. W. M.; Lemstra, P. J. Macromolecules 2010, 43, 2780-2788.

(24) Tuminello, W. H. Polym. Eng. Sci. 1986, 26, 1339-1347.

(25) Stankovich, S.; Dikin, D. A.; Dommett, G. H. B.; Kohlhaas, K. M.; Zimney, E. J.; Stach, E. A.; Piner, R. D.; Nguyen, S. T.; Ruoff R. S. Nature 2006, 442, 282-286. 
(26) Topsoe, H. Geometric factors in four point resistivity measurement. 2nd revised ed. Topsoe Haldor: Vedbaek, 1968.

(27) Tervoort-Engelen, Y. M. T.; Lemstra, P. J. Polym. Commun. 1991, 32, 345.

(28) Marcano, D. C.; Kosynkin, D. V.; Berlin, J. M.; Sinitskii, A.; Sun, Z.; Slesarev, A.; Alemany, L. B.; Lu, W.; Tour, J. M. ACS Nano 2010, 4, 4806-4814.

(29) Brydson, J. A. Plastics Materials, 4th ed. Butterworth-Heinemann: London, 1982.

(30) Pang, H.; Chen, T.; Zhang, G.; Zeng, B.; Li, Z. M. Mater. Lett. 2010, 64, 2226-2229.

(31) Long, G. C.; Tang, C. Y.; Wong, K. W.; Man, C. Z.; Fan, M. K.; Lau, W. M.; Tao, Xu.; Wang, B. Green Chem. 2013, 15(3), 821-828.

(32) Weber, M.; Kamal, M. R. Polym. Comps. 1997, 18 (6), 711-725.

(33) Stauffer, D.; Aharnoy, A. Introduction to Percolation Theory; Taylor \& Francis: London, 1991.

(34) Li, J.; Kim, J. K. Compos. Sci. Technol. 2007, 67, 2114-2120.

(35) Rastogi, S.; Lippits, D. R.; Peters, G. W. M.; Graf, R.; Yao, Y.; Spiess, H. W. Nat. Mater. $\mathbf{2 0 0 5}, 4,635-641$.

(36) Cheng, S. Z. D. Phase transition in polymers: the role of metastable states. Elsevier: Oxford, 2008.

(37) Wang, B.; Li, H.; Li, L.; Chen, P.; Wang, Z.; Cu, Q. Compos. Sci. Technol. 2013, 89, $180-185$. 
(38) Chatterjee, T.; Krishnamoorti, R. Soft Matter. 2013, 9, 9515-9529.

(39) Ferry, J. D. Viscoelastic Properties of Polymers 3rd ed. Wiley: New York, 1980.

(40) Zhang, Q.; Lippits, D. R.; Rastogi, S. Macromolecules 2006, 39, 658-666.

(41) Mackay, M. E.; Dao, T. T.; Tuteja, A.; Ho, D. L.; Brooke van, H.; Kim, H. C.; Hawker, C. Nat. Mater. 2003, $2,762$.

(42) Maurer, F. H. J.; Schoffeleers, H. M.; Kosfeld, R.; Uhlenbroich, T. H. Prog. Sci. Eng. Compos. 1992, 803.

(43) Jain, S.; Goosens, G. W. M.; van Duin, M.; Lemstra, P. J. Soft Matter, 2008, 4, 1848 1854.

(44) Vega, J. F.; da Silva Y.; Vicente-Alique, E.; Nunez-Ramirez, R.; Trujillo, M.; Arnal, M. L.; Muller, A. J.; Dubois, P.; Martinez-Salazar, J. Macromolecules 2014, 47, 5668-5681.

(45) Litvinov, V. M.; Steeman,, P. A. M. Macromolecules 1999, 32, 8476-8490.

(46) Litvinov, V. M.; Orza, R. A.; Klüppel, M.; van Duin, M.; Magusin, P. C. M. M. Macromolecules 2011, 44, 4887-4900.

(47) Yamazaki, S.; Hikosaka, M.; Toda, A.; Wataoka, I.; Gu, F. Polymer 2002, 43, 6585-6593.

(48) Hikosaka, M.; Watanabe, K.; Okada, K.; Yamazaki, S. Adv. Polym. Sci. 2005, 191,137186.

(49) Xu, J. Z.; Zhong, G. J.; Hsiao, B. S.; Fu, Q.; Li, Z. M. Prog. Polym. Sci. 2014, 39, 555593. 


\section{For Table of Contents use only:}
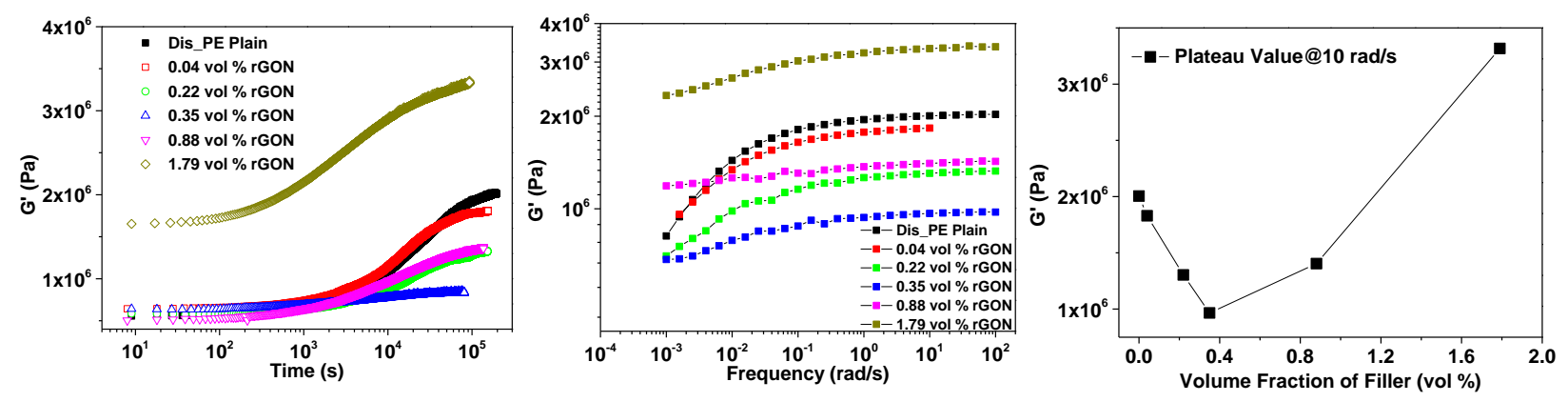

\section{Title of the paper:}

Unique rheological response of the Ultra High Molecular Weight Polyethylenes in the presence

of graphene oxide

Author list of the graphic: Kangsheng Liu, Sara Ronca, Efren Andablo-Reyes, Giuseppe Forte, Sanjay Rastogi 
2

3

4

5

6

7

8

9

10

11

12

13

14

15

16

17

18

19

20

21

22

23

24

25

26

27

28

29

30

31

32

33

34

35

36

37

38

39

40

41

42

43

44

45

46

47

48

49

50

51

52

53

54

55

56

57

58

59

60

ACS Paragon Plus Environment 